\title{
Crime Mapping and Analysis in the Core Area of Akure, Nigeria
}

\section{Olajuyigbe $\mathbf{A}^{1}$, Omole $\mathrm{K}^{1}$, Bayode $\mathrm{T}^{1}$ and Adenigba $\mathrm{A}^{2 *}$}

${ }^{1}$ Department of Urban and Regional Planning, Federal University of Technology, Akure, Ondo State, Nigeria

${ }^{2}$ Space Science Technology, African Regional Centre for Space Science Technology Education in English, Nigeria

\begin{abstract}
Urbanization and increase rate of poverty coupled with the challenges of insecurity in most developing countries have led to increase of crime incidence. This phenomenon is not new to residents of Nigeria cities; it has created unrest and great burden. Consequently, this calls for the development of new approaches to tackle crime incidence in cities. This study therefore focuses on the application of Geographic Information Systems (GIS) as a tool for mapping out the area liable to crime in the core area of Akure, Nigeria. The study employs the use of secondary data. Secondary data include: literatures, journals and crime incidence reports gotten from internet, archives and Nigeria Police Force (NPF) respectively. Both spatial and statistical analyses were carried out using the appropriate tools such as Neighbourhood and Correlation Analysis, respectively. This study revealed that the transport route cutting through Akure metropolis is prone to crime activity. Finally, the study recommends that police officials should be trained on how to use GIS to fight crime.
\end{abstract}

Keywords: Akure metropolis; Crime; Mapping; Poverty; GIS

\section{Introduction}

The traditional and age-old system of intelligence and criminal record maintenance has failed to live up to the requirements of the existing crime scenario. Manual processes have neither provided accurate, reliable and comprehensive data round the clock nor does it help in trend prediction and decision support, asides resulting to lower productivity and ineffective utilization of manpower. The solution to this ever-increasing problem lies in the effective use of Information Technology (IT) to crime management especially in the cities.

A crime is an international act or omission in violation of criminal law, committed without defence or justification and sanctioned by the state as a felony or misdemeanour [1]. Crime is largely an urban phenomenon peculiar to cities, but the specific urban area dimensions of the social processes that are connected with crime have been seriously understated in much recent criminological work. Urban crime is a composite and multidimensional phenomenon which includes behavioural, physiological, managerial, and spatial factors and other various scopes. Correspondingly, Sutherland, Cressey and Luckenbill [2] affirm that the study of crime in its various scopes is a vital area of interest to different groups of people. Sociologists and criminologists believe that crime results from societal anxiety. They associate crime with socio-demographic factors, indicating that the rates of crime in any urban neighbourhood are highly influenced by demographic and socio-economic contexts such as income, ethnic composition, youth concentration and level of education and a host of others without any regard for the spatial configuration of the settings of crime [3]. Crime, in the social and legal framework, is the set of facts or assumptions (causes, consequences and objectives) that are part of a case in which they were committed acts punishable under criminal law, and the application of which depends on the agent of asentence or security measure criminal).

Crime has serious negative effects on societies in both developed and developing countries of the world. Fear of victimization, loss of life and assets, drop in income, unemployment, displacements, evictions, emotional depression and diversion of investment and development funds towards security cost are all impacts of rising incidences of crime in our societies. Despite huge investments in social interventions and crime prevention measures all over the world, the crime problem is still unresolved, as crime rate around the globe continues to escalate due to increasing growth in poverty and the inequality in urban neighbourhoods, manifest through the proliferation of slums and unplanned urban areas in towns and cities. Crime presents a major challenge for the social, economic and physical development of cities and towns all over the world. Hence, the need for more advanced way, technology and methodology to combating crime in which application of GIS will help a great deal through crime mapping.

Crime mapping is an integral and an essential part of crime monitoring, control and management [4] and Geographic Information System (GIS) plays an important role in crime mapping and analysis. Response capabilities often rely on a variety of data from multiple agencies and sources. The ability to access and process information quickly while displaying it in a spatial and visual medium allows agencies to allocate resources quickly and more effectively. In the 'mission-critical' nature of law enforcement, information about the location of a crime, incident, suspect, or victim is often crucial to determine the manner and size of the response. In addition, Yeung, et al. [5], also emphasised that GIS software helps co-ordinate vast amounts of location-based data from multiple sources. It enables the user to stack layers of data and view the data most critical to the particular issue or mission. It is used world over by police departments, both large and small, to provide mapping solutions for crime analysis, criminal tracking, traffic safety, community policing, Intranet/ Internet mapping, and numerous other tasks [6]. Crime analysis involves the collection and analysis of data pertaining to a criminal incident, offender, and target. Crime analysis can be used to evaluate the effectiveness of programs such as community policing and crime

*Corresponding author: Agboola David Adenigba, Space Science Technology, African Regional Centre for Space Science Technology Education in English, Nigeria, Tel: 2348089784257; E-mail: adenigbaagboola@gmail.com

Received November 04, 2016; Accepted November 15, 2016; Published November 17, 2016

Citation: Olajuyigbe A, Omole K, Bayode T, Adenigba A (2016) Crime Mapping and Analysis in the Core Area of Akure, Nigeria. J Remote Sensing \& GIS 5: 178. doi: 10.4172/2469-4134.1000178

Copyright: (c) 2016 Olajuyigbe A, et al. This is an open-access article distributed under the terms of the Creative Commons Attribution License, which permits unrestricted use, distribution, and reproduction in any medium, provided the original author and source are credited. 
prevention, develop policy through research, justify budget requests, and help identify or define a problem [7]. Geographic Information System (GIS) and Remote Sensing (RS) provide the medium for the integration of spatial data. GIS and remote sensing have been widely recognized as an effective tool for planning and decision-making tasks. They allow for effective storage, manipulation and analysis of geographical data.

In a strict legal definition, however, a crime is a violation of criminal law which in most societies can be defined broadly as any 'act or omission forbidden law on pain of punishment'. The cost of crime is another aspect relating to urban violence. Two costs of violence can be identified; these are monetary as well as non-monetary otherwise referred to as social cost [8]. Perceptions of crime are not determined by an objective indicator of the degree of injury or damage but by cultural values and power relations (UN, 1995).

In Nigeria, a good number of facts and incidents aid and abet the awareness of crime rate, analysis and mapping. The awareness that crime is not evenly distributed across cities, but often concentrated in certain areas has been the focus of crime study since 1940s, thus given prominence to environmental criminology as a field of the study of the influence of situational factors (social and physical) on crime and travel behaviour of criminals across urban neighbourhoods $[9,10]$. Crime mapping and analysis is a relatively new area with the origin in United State of America and spreading to the United Kingdom in the recent times. Little or nothing had been written about the effectiveness of crime mapping and analysis generally in Nigeria and in particular to the security maintenance and functionality in Nigeria.

Research evidence suggests that both physical and social conditions of the environment may influence crime incidents and make certain neighbourhoods crime prone and others less crime prone thus generating different patterns of crime and crime analysis travel across a city $[11,12]$. The geography of crime with its emphasis on mapping and spatial analysis has emerged in recent years as a growing area of research. However, 'cartographic criminology' involving the production of maps indicate the distribution of crime is found not enough for the modern day crime analysis, rather, the requirements today involves the need to explore the relationship between sociospatial phenomenon and crime pattern through a more robust spatial and statistical analysis tools present in the modern day Geographic Information System (GIS) and Remote Sensing (RS) [9].

The immediate response of most people to crime is fear. Although several factors have identified as the cause of fear in relation to crime, one general feature of crime is that high level of fear are not only dependent on actual personal victimization. A study confirmed that there is little difference in the levels of fear of crime between victims and non-victims. In essence, the high level of fear of crime perceived by the residents may not necessarily match the risk of personal victimization. A comparison of the historical situation with the present suggests that recent interest in crime mapping is likely to have a more substantial and lasting impact on crime prevention theory and applications. A review of literature shows that a combination of different physical and social variables may impact crime at various stations in a specific area, neighbourhood or regions. Researchers have argues that defensible space characteristics of residential apartment design (such as lighting, fencing, specific security hardware, and open design that allows opportunities for surveillance) can discourage crime activities.

This research further shows that the urban characteristics of neighbourhoods are important for crime. Particular land uses (e.g., schools, bars, stores, and abandoned buildings) have been found to attract more crime in their vicinity [13-15]. The presence of physical disorder and incivility, signified by deteriorating building stock and public environments, with concentration of graffiti and litteris also likely to have an impact on neighbourhood crime $[16,17]$.

As previously noted, researchers have also hypothesized that compositional characteristics of the neighbourhood surrounding densely populated area, income levels, age, educational level, and unemployment level of residents have a likely correlation with crime operations. A violent crime or crime of violence is a crime in which the offender uses or threatens to use violent force upon the victim. This entails both crimes in which the violent act is the objective, such as murder, as well as crimes in which violence is the means to an end, (including criminal ends) such as robbery. Violent crimes include crimes committed with weapons. With the exception of rape (which accounts for $6 \%$ of all reported violent crimes), males are the primary victims of all forms of violent crime.

Spatial or geo-information in the form of maps, plans, aerial photographs, satellite imageries among others have always formed the physical base on which settlements development planning is undertaken. It has earlier been emphasized that the ability of cities to manage urban growth is increasingly dependent on timely access to spatial information and the competence of turning these data into information to support decision-making. The rapid advancement and proliferation of GIS has increased interest in crime mapping and analysis due to its ability to aggregate different data sources and converting them into useful information in understanding and predicting a pattern $[18,19]$. Furthermore, the analytical application of GIS and RS can be used in either an exploratory or confirmatory capacity.

Crime mapping is a term that has been used for the past few years to refer to research analysis using GIS in a law enforcement setting. Crime analysis mapping is used to describe this process because using a GIS to analyze crime is not just the act of placing incidents on a map but also of analysis [20]. It is also the process of using a geographic information system in combination with crime analysis techniques to focus on the spatial context of criminal and other law enforcement activity. Maps offer crime analysts graphic representations of crimerelated issues. An understanding of where and why crimes occur can improve attempts to fight crime. Mapping crime can help police protect citizens more effectively. Simple maps that display the locations where crimes or concentrations of crimes have occurred can be used to help direct patrols to places they are most needed. Policy makers in police departments might use more complex maps to observe trends in criminal activity, and maps may prove invaluable in solving criminal cases [6]. To this end, this paper demonstrates the effectiveness of GIS to crime mapping in the core area of Akure, Nigeria.

\section{Material and Methods}

\section{The Study area}

The study area falls within Akure south, the capital of Ondo State, Nigeria. Akure is located between latitude $7^{\circ} 17^{\prime} \mathrm{N}$ and longitude $5^{\circ} 4$ ' $\mathrm{E}$ with a coverage area of $318.0 \mathrm{~km}^{2}$. Akure is about $370 \mathrm{~m}$ above the mean sea level. Akure is bounded to the South by Idanre; to the East by Owo and to the North by Ifedore Local Government Area. The easy access and geographical centrality of Akure to these neighbouring towns have enhanced the growth prospects of the city. Okoko asserted that, this influx was necessitated by the development attracted to the state capital. With the presence of government seat in Akure, job opportunities, 
provision of community facilities such as roads, water etc., and social facilities such as hospitals, schools, markets etc., precipitated the migration of youths from the surrounding towns/settlements for job opportunities among others, leading to increase in population. In 2006, the population of Akure was 387,100 (NPC, 2006). However, the population of Akure is estimated to be 1.8 million by 2015. This growth will be as a result of industrial growth; its classification as among oil producing state and millennium development city (Figure 1). Akure falls within the tropical rain forest region of Nigeria where rain fall is high. The mean annual rainfall is about $250 \mathrm{~cm}$, the atmospheric temperature ranges between $28^{\circ} \mathrm{C}$ and $31^{\circ} \mathrm{C}$ and a mean annual relative humidity of about 80 per cent [21].

\section{The Data base}

This study is descriptive in nature, involving the use of secondary and primary data with the integration of Geographic Information System techniques. Secondary data used for the study were sourced from journals, archives, library and institutions. They include: analogue maps of the study area, crime data in the region from the Police Headquarters and Crime Reports. Primary data which include field data were gotten with use of Global Positioning System (GPS). The data were analysed and presented by the use of maps to explain the distribution of crime incidents in the study area. The software used for data analysis include: ArcGIS 10.0, CrimeStat III, Global Mapper 13.0,
Map Source, and Transfo (used for converting geographic (angular) coordinates to UTM coordinates [22-24].

\section{Analysis using Geographic Information System (GIS)}

For this study, GPS Garmin 76 was employed to obtain coordinates of major landmarks in the study area in other to register these landmarks; which comprises of police stations, banks, markets, liquor stores, and place of worship. The crime data gotten on field through GPS were transferred into Microsoft Excel and imported into ArcGIS 10 for geocoding. Advanced spatial analysis such as hotspot and black spot analysis using Geostatistical Analyst which includes Inverse Distance Weight analysis, Kriging and Cokriging.

Geostatistical analyst provides tools that make the best prediction possible by examining the relationship between all the sample points and producing a continuous surface of crime concentration, standard errors (uncertainty) of prediction, and probabilities that critical values are exceeded. This analysis tool bridges the gap between geostatistic and GIS. Examples of geostatistical operations includes: Inverse Distance Weighing (IDW), Kriging, Kernel Kriging, Cokriging etc. They are all interpolation techniques [25].

\section{Analysis of Findings and Discussion}

As asserted earlier, IDW was adopted for this study to interpolate the data gotten through the GPS. From the analysis as shown in Figure 2,

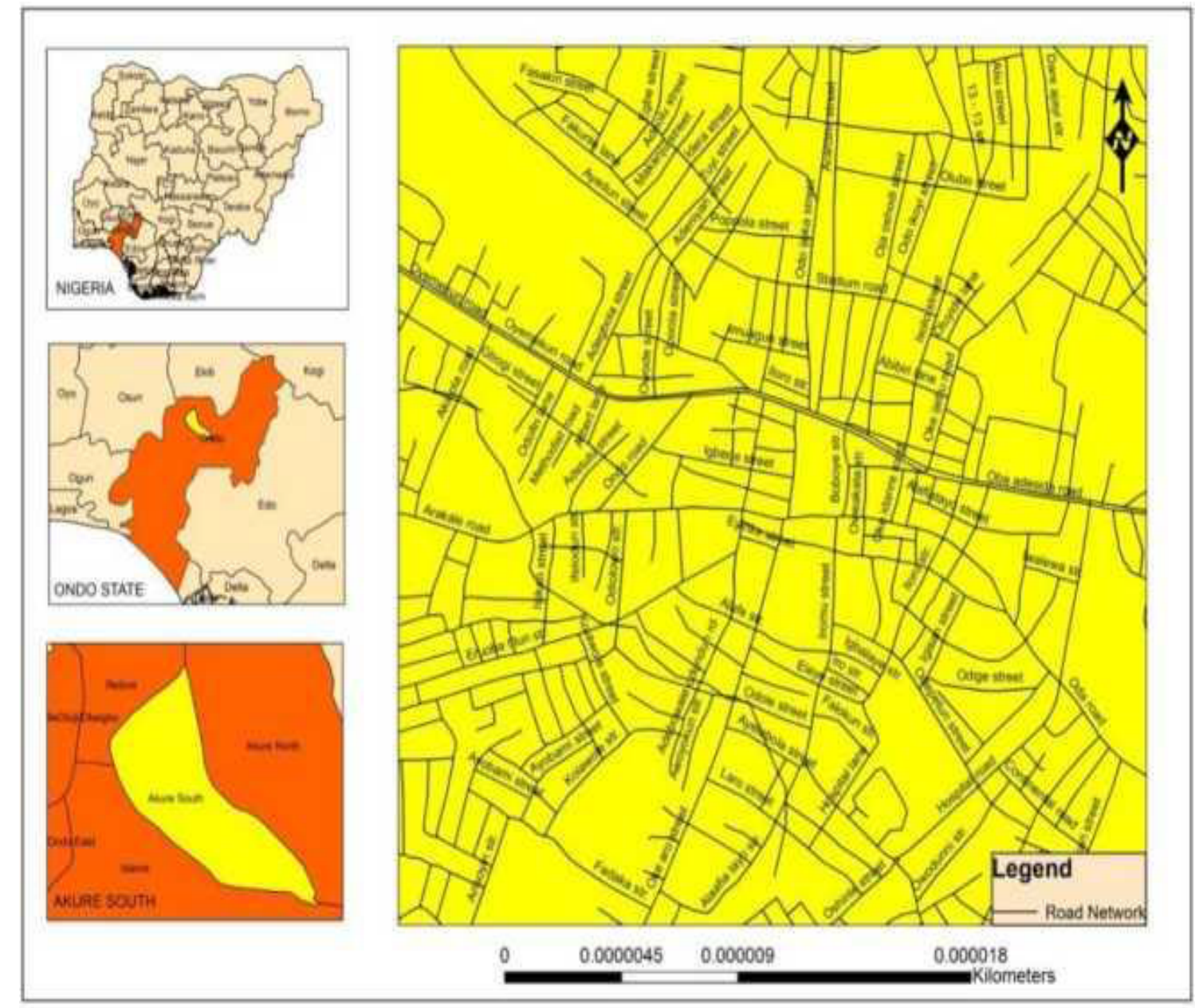

Figure 1: Study area map. 

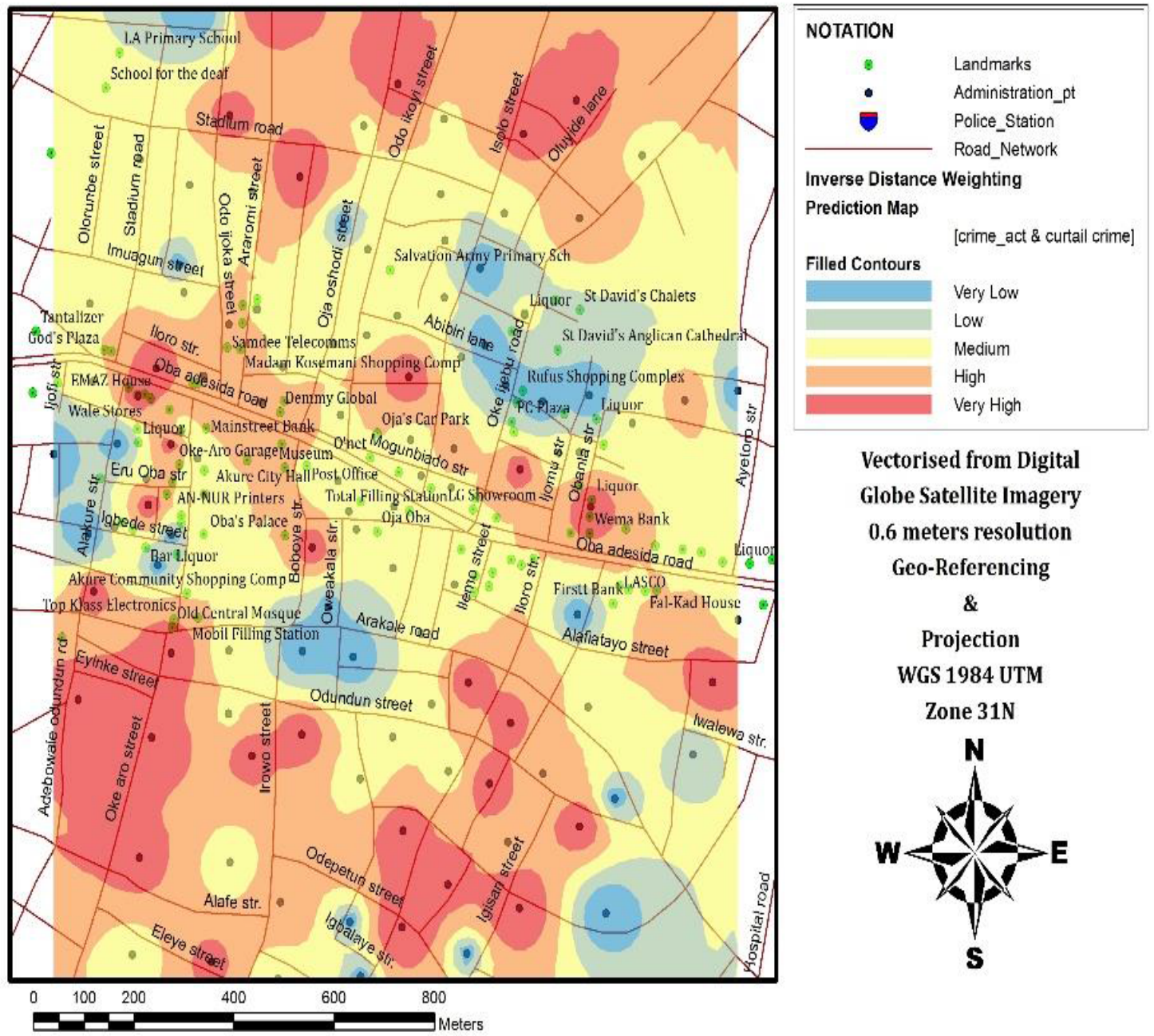

\section{Vectorised from Digital}

Globe Satellite Imagery

0.6 meters resolution

Geo-Referencing

$\&$

Projection

WGS 1984 UTM

Zone 31N

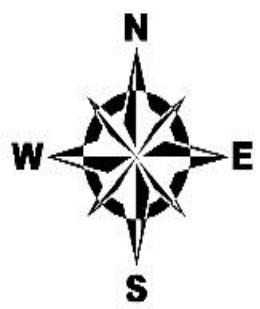

Figure 2: Map showing geospatial analysis of level of crime in the study area.

the study revealed that the intensity of crime is on the increase along the major transport route cutting through Akure metropolis, and also to some specific areas such as Post-Office, Oke-Aro, Odo-Ikoyi and Isolo etc. This is as a result of the poor policing and concentration of activities in these areas. From the study, it was also revealed that police protection with respect to crime and violent act is poor taking into consideration the affected areas in the study area. The ineffectiveness of the police with regards to the respondents view was paramount around various strategic centre of attraction such as the God's Plaza (Nao Supermarket), LASCO, First Bank, WEMA Bank, Ricobin House, BIZ Leonac Mega Plazaetc and even to some interior part of the Akure city core.

From the result of analysis using the cokriging factor, the multiple datasets to investigate cross correlation and autocorrelation, shows that analyzing of multivariable proves to be a useful way of deducing crucial factors. The combination of these variables (gang activity in the area, paramount property crime and paramount personal crime) shows that the flux of crime in the study area is at a peak level. The major event areas are carried out along the Oba Adesida road and gradually reducing to the exterior part of the Akure Metropolitan core.

Police security management in the area is grossly below average. From the analysis, the respondent strongly believed that police security management is rather poor as the Force does not have sufficient manpower and combating factor to keep the study area healthy from the unrest of crime and violent act (Figures 2-5).

\section{Recommendations and Conclusion}

This study is based on crime mapping and analysis in Akure city core centre. The occurrence of such activities must be curtailed through a viable planning to increase the security apparatus of the state capital. Again, the police force has not being able to apprehend the occurrence of criminal activities in the study area due to weak capacity. From the field survey, it was revealed that the crime activities are more dominant in some part of the city core compare to others. This study has been able to develop crime database system that could increase security around the Akure city core. Such system will achieve greatly in the detections of hotspots and black spots, generation of maps indicating neighbourhoods that lack security facilities, knowledge of crime pattern and occurrence, crime prediction among others. This system will not only assist Ondo State in crime reduction but other states in the country if adopted.

Based on the findings, the study recommended that the state government promptly embark on the provision of security in the state 

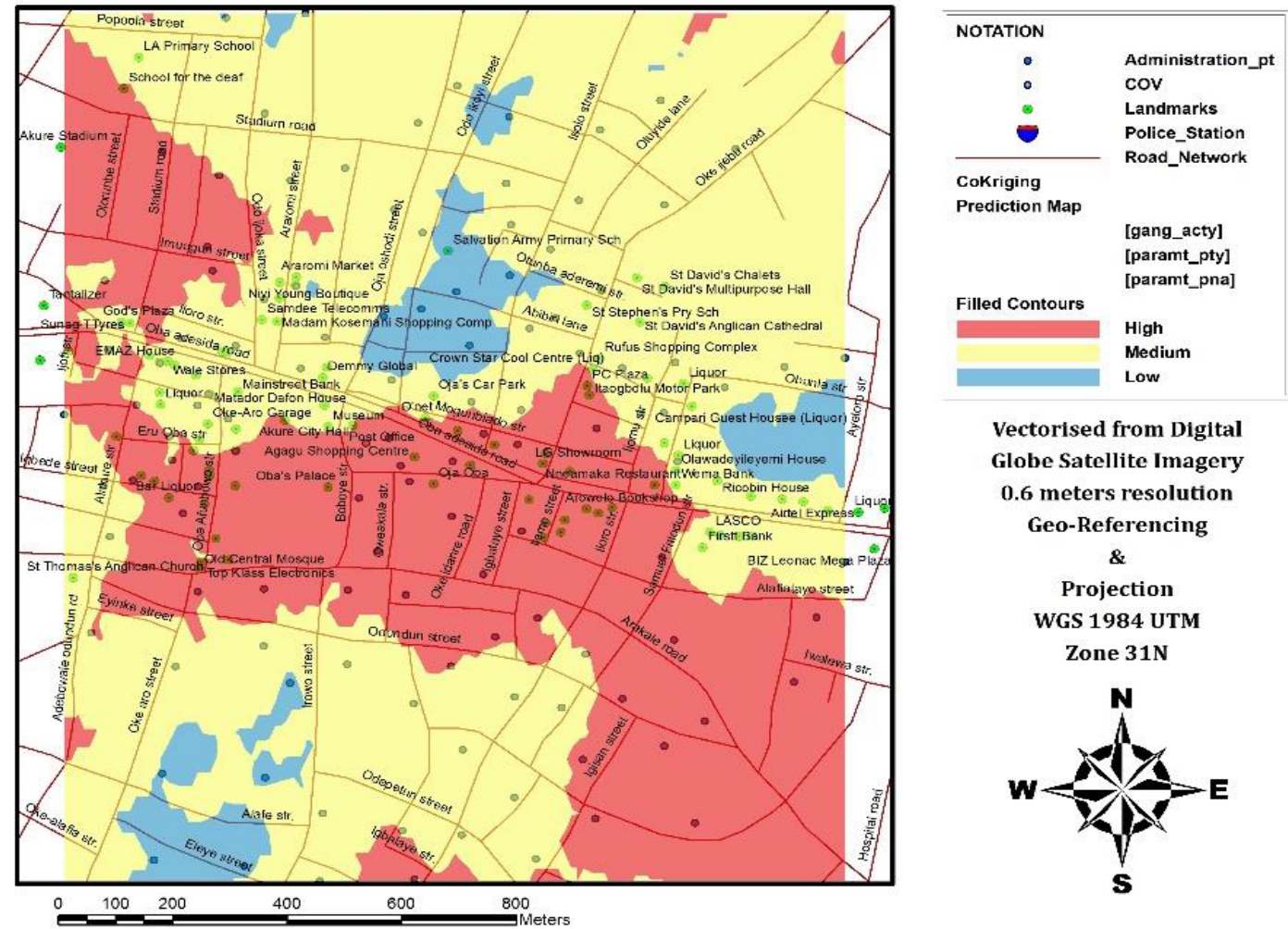

Vectorised from Digital

Globe Satellite Imagery

0.6 meters resolution

Geo-Referencing

$\&$

Projection WGS 1984 UTM

Zone 31N

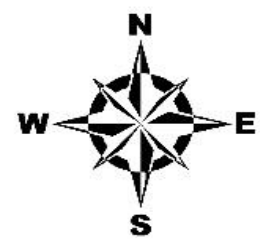

Figure 3: Geospatial analysis of gang activity with respect to property and personal crime.
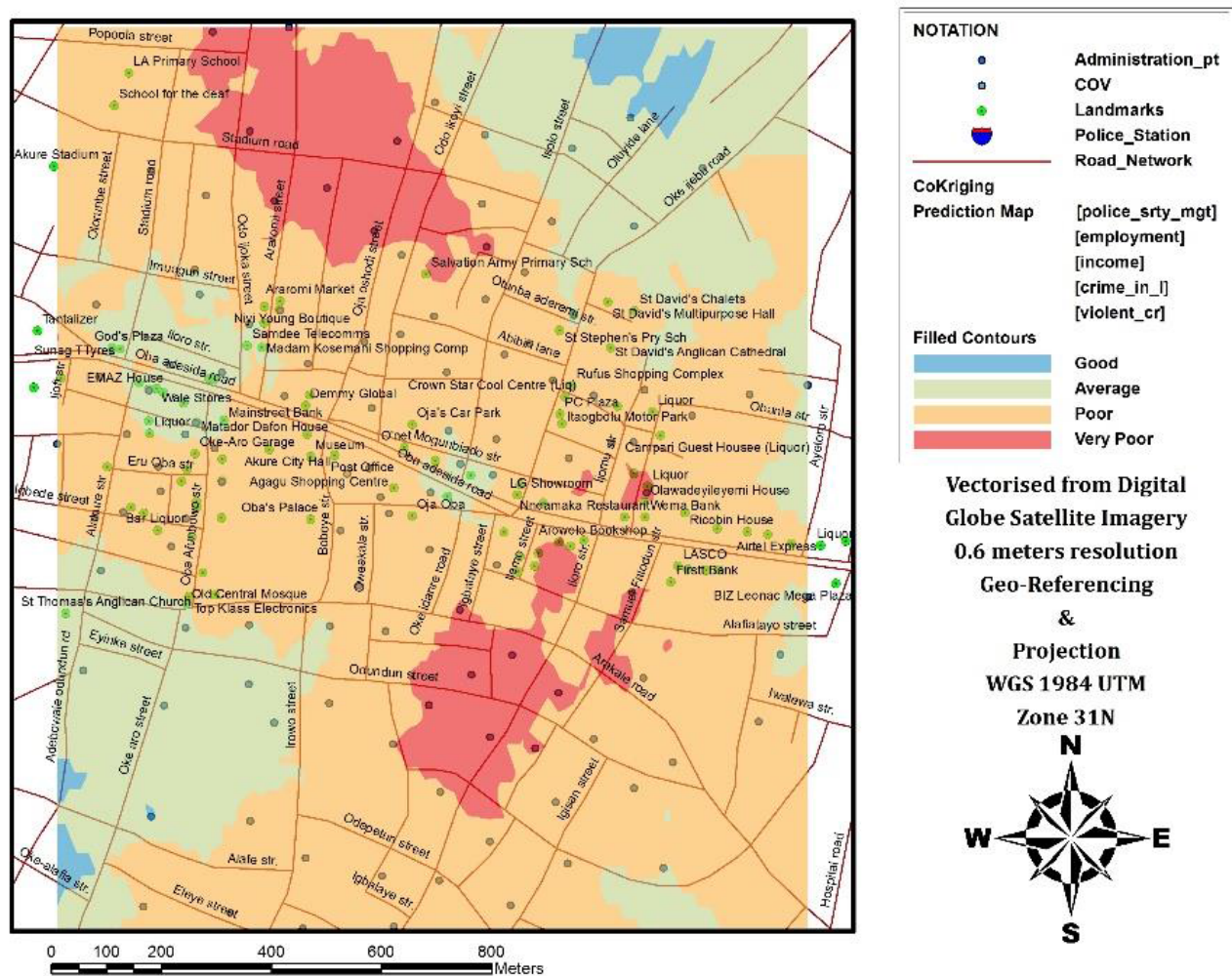

Vectorised from Digital

Globe Satellite Imagery

0.6 meters resolution

Geo-Referencing

Projection WGS 1984 UTM

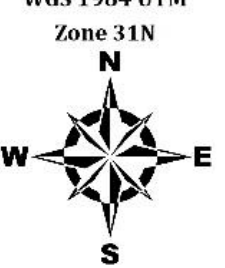

Figure 4: Map showing geospatial analysis of police security management in the study area. 


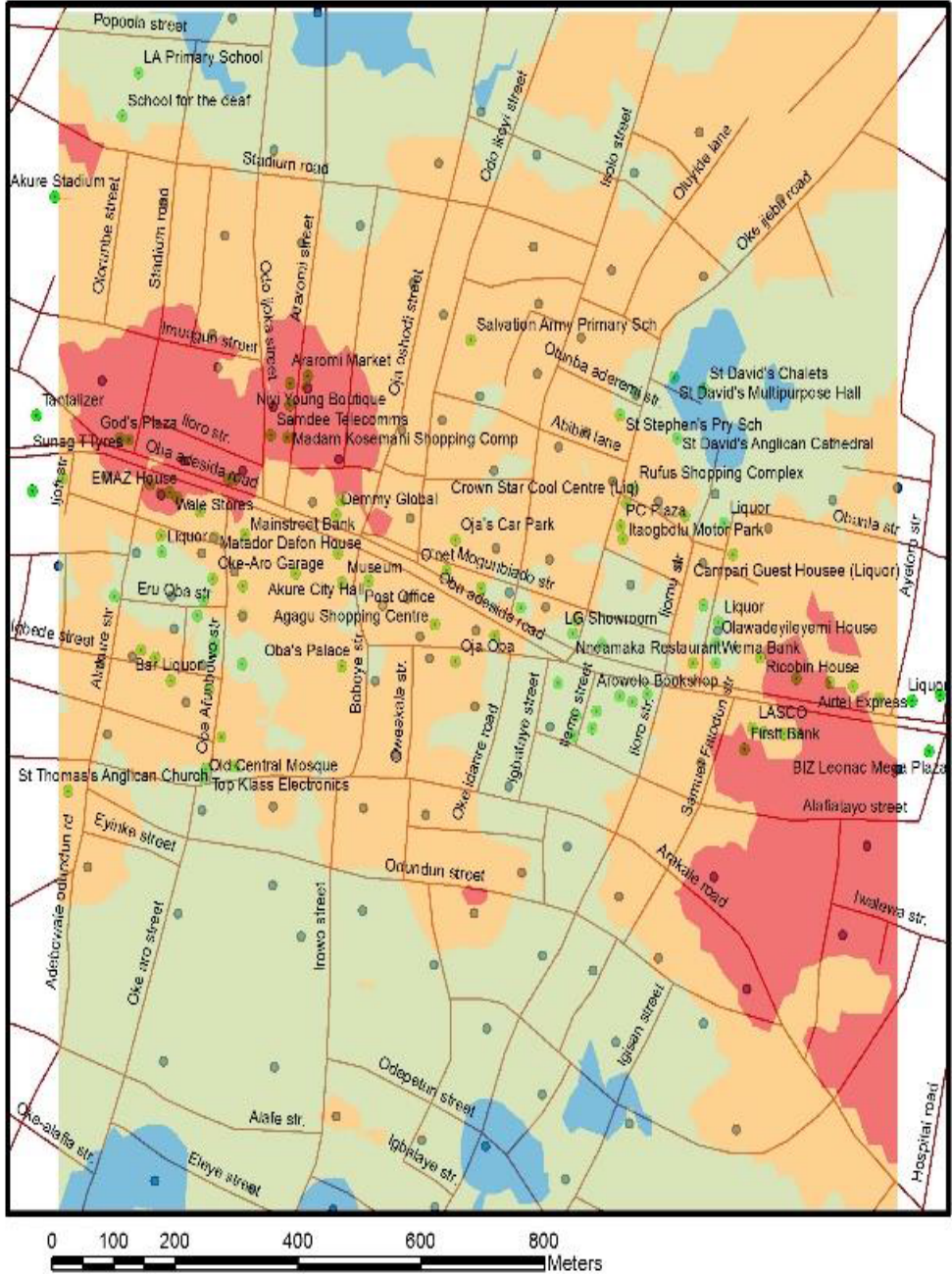

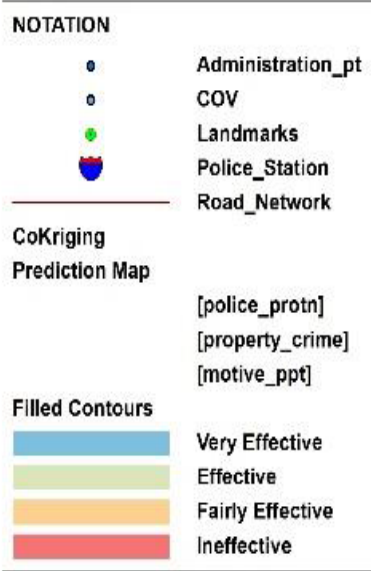

Vectorised from Digital

Globe Satellite Imagery

0.6 meters resolution

Geo-Referencing

\&

Projection

WGS 1984 UTM

Zone 31N

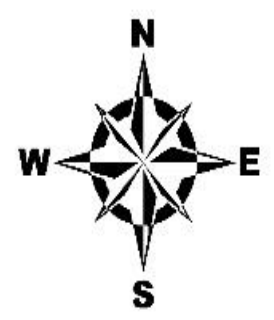

Figure 5: Geospatial analysis of gang activity with respect to Police protection, property crime and motive towards crime.

capital. This is an urgent need in the study area because the reoccurring events of criminal acts are unending. The government should recognise the importance of life and property to economic growth. This can be actualize if the government should invest adequate funds in the Nigerian Police Force including capacity training programme and mind-set change as a means to curtailing crime activity in the state capital. There should be constant police patrol in the city core. Recruitment of man power into police force should not be based on the need for employment at all cost, but on the passion and desire to be a protector of the safety of the people.

\section{References}

1. Reid ST (1991) Crime and Criminology. 6th edn., Fort Worth Publishers, USA, p: 687.

2. Sutherland EH, Cressey DR, Luckenbill DF (1992) Principles of criminology. Rowman and Little field Publishers, Maryland, USA, p: 696

3. Reith M (1996) The Relationship between Unemployment in Society and the Popularity of Crime Drama on TV. Journal of Broadcasting and Electronic Media 40: 258-264

4. Alex H, Kate B (2003) Mapping and Analyzing Crime Data: Lessons from Research and Practice. 2nd edn. Taylor and Francis, London.
5. Yeung AK, Hall GB (2007) Spatial Data and Spatial Database Systems. In Spatial Database Systems, Springer, Netherlands, pp: 93-127.

6. Johnson CP (2000) Crime Mapping and Analysis Using GIS. Geomatics Group, C-DAC, Pune University Campus, Pune, India, pp: 1-5.

7. Philip C (1999) Using a Geographic Information System for Tactical Crime Analysis. Analyzing prime patterns, Sage publications, New Delhi, India, pp 1-179.

8. Agboola T (2001) A Profile of Violence, Urban Insecurity and Prevention in the City of Abuja, Nigeria. A Report Submitted to the Safer Cities Programme, United Nation Centre for Human Settlement, HABITAT, Nairobo, Kenya.

9. Hebert DT (1989) Crime and Place: An Introduction. In: Evans DJ, Herbert DT (eds.), The Geography of Crime, London and New York, USA.

10. Davies M, Mousas J (2007) Homicide in Australia: 2005-2006 Nationa Homicide Monitoring Program Annual Report, Research and Public Policies Series No. 77. Australian Institute of Criminology, Canberra, Australia.

11. Greenberg S, Rohe W, Williams J (1985) Informal citizen's action and crime prevention at the neighbourhood level: Synthesis and assessment of the research-Executive Summary. National Institute of Justice Executive Summary, RTI International, USA.

12. Newman O (1976) Design Guidelines for Creating Defensible Space. US Government Printing Office, Washington DC, USA

13. Block RL, Block CR (2000) The Bronx and Chicago: Street Robbery in the 
Citation: Olajuyigbe A, Omole K, Bayode T, Adenigba A (2016) Crime Mapping and Analysis in the Core Area of Akure, Nigeria. J Remote Sensing \& GIS 5: 178. doi: 10.4172/2469-4134.1000178

Page 7 of 7

Environs of Rapid Transit stations. In: Goldsmith V, McGuire PG, Mollenkopf $\mathrm{JH}$, Ross TA, (eds.) Analyzing Crime Patterns: Frontiers of Practice. Sage Publications; Thousand Oaks, CA, USA, pp: 137-152.

14. Block RL, Block CR (1995) Space, Place, and Crime: Hot Spot Areas and Hot Places of Liquor-Related Crime. In Eck J, Weisburd D (eds.), Crime and Place, Monsey, Willow Tree Press, New York.

15. Greenberg S (1986) "Fear and its Relationship to Crime, Neigbour hood Deterioration, and Informal Social Control." In Byrne J, Sampson RJ (eds.), The Social Ecology of Crime, Springer-Verlag, New York, USA, pp: 47-62.

16. Perkins DD, Abraham A, Richard R, Taylor B (1993) The Physical Environment of Street Crime: Defensible space, territoriality and incivilities. Journal of Environmental Psychology 13: 29-49.

17. Skogann WG (1990) Disorder and Decline: Crime and the Spiral of Decay in American Neighborhoods. MacMillian, New York.

18. Longley P, Clarke G (1995) GIS for Business and Service Planning. GeoInformation Information, Cambridge, USA.

19. Bowers K, Hirschfield A (1999) Exploring links between crime and disadvantage in north-west England: An analysis using geographical information systems. International Journal of Geographic Information Science 13: 159-184.

20. Racheal B (2001) Introductory Guide to Crime Analysis and Mapping. Office of Community Oriented Policing Services, US Department of Justice, Washington DC, USA, pp:1-74.

21. Ajibefun I (2014) Akure City Profile. International Water Management institute, Columbo, USA.

22. Byrne J, Sampson RJ (1986) "Cities, Citizens, and Crime: The Ecological/ Nonecological debate Reconsidered. The Social Ecology of Crime, SpringerVerlag, New York, pp: 77-101.

23. Clarke RV (1995) "Situational crime prevention" In Building a Safer Society: Strategic Approaches to Crime Prevention, Michael T, Farrington D (eds.), The University of Chicago Press, Chicago, USA.

24. NIJ (2016) Department of Justice, National Institute of Justice, Washington DC USA.

25. Kothari CR (2004) Research methodology: methods and techniques. 2nd edn New Age International Publishers, India. 